\title{
The effect of the muscle environment on the regenerative capacity of human skeletal muscle stem cells
}

Jinhong Meng, Maximilien Bencze, Rowan Asfahani, Francesco Muntoni and Jennifer E Morgan*

\begin{abstract}
Background: Muscle stem cell transplantation is a possible treatment for muscular dystrophy. In addition to the intrinsic properties of the stem cells, the local and systemic environment plays an important role in determining the fate of the grafted cells. We therefore investigated the effect of modulating the host muscle environment in different ways (irradiation or cryoinjury or a combination of irradiation and cryoinjury) in two immunodeficient mouse strains ( $m d x$ nude and recombinase-activating gene (Rag)2-/Y chain-/C5-) on the regenerative capacity of two types of human skeletal muscle-derived stem cell (pericytes and CD133+ cells).

Methods: Human skeletal muscle-derived pericytes or CD133+ cells were transplanted into muscles of either mdx nude or recombinase-activating gene (Rag)2-/Y chain-/C5- host mice. Host muscles were modulated prior to donor cell transplantation by either irradiation, or cryoinjury, or a combination of irradiation and cryoinjury. Muscles were analysed four weeks after transplantation, by staining transverse cryostat sections of grafted muscles with antibodies to human lamin $A / C$, human spectrin, laminin and Pax 7 . The number of nuclei and muscle fibres of donor origin and the number of satellite cells of both host and donor origin were quantified.
\end{abstract}

Results: Within both host strains transplanted intra-muscularly with both donor cell types, there were significantly more nuclei and muscle fibres of donor origin in host muscles that had been modulated by cryoinjury, or irradiation+cryoinjury, than by irradiation alone. Irradiation has no additive effects in further enhancing the transplantation efficiency than cryodamage. Donor pericytes did not give rise to satellite cells. However, using CD133+ cells as donor cells, there were significantly more nuclei, muscle fibres, as well as satellite cells of donor origin in Rag2-/y chain-/C5- mice than mdx nude mice, when the muscles were injured by either cryodamage or irradiation+cryodamage.

Conclusions: Rag2-/Y chain-/C5- mice are a better recipient mouse strain than mdx nude mice for human muscle stem cell transplantation. Cryodamage of host muscle is the most effective method to enhance the transplantation efficiency of human skeletal muscle stem cells. This study highlights the importance of modulating the muscle environment in preclinical studies to optimise the efficacy of transplanted stem cells.

Keywords: Human skeletal muscle stem cells, Transplantation, Animal model, Immunodeficiency, Rag2-/Y chain-/C5- mice, $m d x$ nude mice, Stem cell therapy, Satellite cells

\footnotetext{
* Correspondence: jennifer.morgan@ucl.ac.uk

The Dubowitz Neuromuscular Centre, Molecular Neurosciences Section,

Developmental Neurosciences Programme, UCL Institute of Child Health, 30

Guilford Street, London WC1N 1EH, UK
} 


\section{Background}

Muscular dystrophies are a group of inherited diseases characterised by muscle weakness and wasting. A common and severe form of muscular dystrophy is Duchenne muscular dystrophy (DMD), caused by mutations in the dystrophin gene. Typical pathological changes within the muscles of a DMD patient include progressive degeneration and regeneration of muscle fibres, accompanied by the exhaustion of muscle-resident stem cells such as satellite cells, leading to a net loss of muscle fibres that are eventually replaced by fibro-fatty tissue [1]. Transplantation of stem cells has been suggested as a promising way to treat DMD, as donor cells would repair and regenerate muscle fibres; stem cells derived from normal donors would also restore dystrophin expression within these regenerated muscle fibres. If the donor cells also formed functional satellite cells to replenish the muscle stem cell pool, this should provide a long-term source of fibres in DMD patients.

However, stem cells need to be extensively tested in laboratory animal models to elucidate their suitability for clinical application, and it is important that an appropriate animal model is used. Different types of dystrophindeficient [2-6] or non-dystrophic host mice [7-13] have been used for this purpose. For donor stem cells of human origin, this represents xenografting, which requires the host mouse to be profoundly immunodeficient. To augment engraftment of intra-muscularly transplanted human as well as mouse muscle stem cells, the host muscle needs to be modulated prior to cell transplantation. Although the needle used to deliver donor cells intra-muscularly does cause local injury, this may not be sufficient to promote donor cell engraftment. For example, either freshly isolated mouse satellite cells or a single myofibre bearing satellite cells give rise to little, if any, muscle of donor origin after their transplantation into non-injured host $m d x$ nude mouse muscles [14,15]. Although mouse myoblasts do give rise to regenerated muscle fibres in non-injured $m d x$ nude or recombinaseactivating gene (Rag)2-/ $\gamma$ chain-/C5- host muscles, they form significantly less muscle than when grafted into muscles in mice of both strains that had been irradiated with 18 Gy 3 days before grafting [16]. Human myoblasts also gave rise to less muscle of donor origin when transplanted into non-injured compared to cryoinjured host muscles [6,7].

In a preliminary study, we injected human skeletal muscle-derived CD133+ cells or pericytes into non-injured host $m d x$ nude $(n=2)$ or Rag2-/ $\gamma$ chain-/C5- $(n=2)$ mouse muscles, and no cells or muscle fibres of donor origin were detected in these grafted muscles (data not shown). Thus, we considered that the modulation to the host muscle induced by needle injury and cell injection is not sufficient to elicit effective engraftment of human muscle stem cells.
Indeed, different muscle pre-treatment regimes have been used by different groups, including irradiation [7,14-17], cryoinjury $[11,18,19]$ or injection of myotoxin $[20,21]$. The precise mechanism underlying the effect of these pretreatments is not completely clear. In one study, the effect of pre-injury of host muscle with cardiotoxin or cyoinjury on human myoblast engraftment in host muscles was investigated [12], but no systematic comparison has been performed by using different modalities to modulate the engraftment efficiency of human stem cells within host muscles.

In addition, the effect of the host mouse strain on donor stem cell engraftment is not known. The Rag2- $/ \gamma$ chain-/C5- mouse is a triple knockout immunodeficient mouse that has been used for human myoblast transplantation studies $[7,12,22,23]$. The lack of recombinaseactivating gene Rag2 results in total inability to initiate $\mathrm{V}(\mathrm{D}) \mathrm{J}$ rearrangement, leading to a severe combined immune deficient (SCID) phenotype [24]. Deletion of the common cytokine receptor $\gamma$ chain gene results in reduced numbers of peripheral $\mathrm{T}$ and $\mathrm{B}$ lymphocytes and absence of natural killer (NK) cell activity $[25,26]$. A further deletion of the $\mathrm{C} 5$ component of the complement cascade leads to a defect in innate immunity [12]. The combination of knocking out these three molecules makes this mouse an ideal animal model for xenografts, including human muscle stem cell transplantation [7,12,22,23], but the mouse is not dystrophic.

An alternative to test the efficacy of donor stem cells to treat a muscular dystrophy is a mouse model of a human muscular dystrophy, which is also immunodeficient. The $m d x$ mouse lacks dystrophin in skeletal muscles bodywide and is a much-used model of DMD $[27,28]$. However, it has rare, naturally occurring revertant fibres $[29,30]$ that have to be taken into account when assessing donor stem cell-mediated restoration of dystrophin. The $m d x$ mouse has been put on immunodeficient backgrounds including nude [16,31] and SCID [3,4]. More recently, two novel immunodeficient dystrophin-deficient mouse models were developed as hosts for cell transplantation that had either fewer revertant fibres than $m d x$ [2] or a complete absence of dystrophin [6].

The $m d x$ nude mouse has been used extensively as recipient animal model to analyse the regenerative capacity of muscle stem cells of mouse [14,15,27,31-33] and human origin [5]. However, the nude mouse lacks the majority of the T-cells due to the deletion of Foxn1 (winged-helix/ forkhead transcription factor) gene [34] but maintains normal B cell function and high NK cell activity, thus is less immunodeficient than the Rag2-/ $\gamma$ chain-/C5- mouse.

In this study, we aimed to determine whether and to what extent the modulation of host muscle environment would affect the outcomes of stem cell transplantation. To do this, we used two types of stem cell derived from 
human skeletal muscle - human skeletal muscle-derived stem cells, or pericytes [5], and CD133+ cells [10], and compared their transplantation efficiency in Rag2- $/ \gamma$ chain-/C5- and $m d x$ nude mouse muscles that had been modified by either irradiation, or cryoinjury, or a combination of both. Our results show that the ability of the grafted human stem cells to participate in muscle regeneration and to reconstitute the satellite cell pool is dependent on both the recipient mouse strain and the way in which the host muscle is modulated prior to cell transplantation.

\section{Methods}

\section{Ethics}

Human cells were obtained from the MRC Centre for Neuromuscular Diseases Biobank. Tissue sampling was approved by the NHS National Research Ethics Service, Hammersmith and Queen Charlotte's and Chelsea Research Ethics Committee: setting up of a rare diseases biological samples bank (biobank) for research to facilitate pharmacological, gene and cell therapy trials in neuromuscular disorders (REC reference number 06/Q0406/33) and the use of cells as a model system to study pathogenesis and therapeutic strategies for Neuromuscular Disorders (REC reference 13/LO/1826), in compliance with national guidelines regarding the use of biopsy tissue for research. All patients or their legal guardians gave written informed consent for the collection and use of their cells.

Animal experiments were approved by University College London's Animal Welfare Ethical Review Body. Mice were bred and experimental procedures were carried out in the Biological Services Unit, University College London Institute of Child Health, in accordance with the Animals (Scientific Procedures) Act 1986. Experiments were performed under Home Office licence 70/7086.

\section{Human skeletal muscle-derived stem cells}

Human pericytes were isolated from the extensor digitorum brevis muscle of an 11-year-old DMD patient, as described previously [5]. Human skeletal muscle-derived CD133+ cells were isolated from the para-spinal muscle of a 15-year-old boy with adolescent idiopathic scoliosis, using a previously described protocol $[3,10]$.

Both types of cell were maintained in vitro in Megacell DMEM (Sigma-Aldrich, Dorset, UK) containing 10\% fetal bovine serum (FBS) (Invitrogen, Paisley, UK). Pericytes were transplanted at mean population doubling (mpd) 13.58 to 18.90 and CD133+ cells at mpd 6.8 to 7.91(Additional file 1: Table S1).

\section{Mouse strains and muscle injury models}

Host mice aged 4 to 8 weeks were used for this study. Two immunodeficient mouse strains, Rag2-/ $\gamma$ chain-/C5$[16,23]$ and $m d x$ nude $[16,31]$ mice, were used as hosts.
Host tibialis anterior (TA) muscles were modulated in three different ways prior to the injection of donor cells.

Irradiation: 3 days before intramuscular transplantation of donor cells, mice were anaesthetised with hypnorm and hypnovel and 18 Gy radiation, at a dose rate of $0.72 \mathrm{~Gy} / \mathrm{min}$, was administered to the hind limbs [35].

Cryodamage: immediately prior to donor cell transplantation, host mice were anaesthetised with isoflurane and TA muscles cryoinjured, as described previously [7].

Irradiation+cryodamage: hind limbs were irradiated with 18 Gy as described above and then 3 days later, TA muscles were cryoinjured immediately prior to cell transplantation.

\section{Donor cell transplantation}

In $5 \mu$ of medium, $5 \times 10^{5}$ human muscle stem cells were injected into each host TA muscle, using a 5- $\mu \mathrm{l}$ Hamilton syringe.

For human muscle stem cell transplantation, four sets of experiments were performed using both types of muscle stem cell (Additional file 1: Table S1).

\section{Analysis of grafted muscles}

Four weeks after transplantation, grafted muscles were removed for analysis. Ten-micrometer transverse sections were cut throughout the muscle with a Leica cryostat 1850, mounted onto Polysine adhesion slides (VWR, Leicestershire, UK) and stored at $-80^{\circ} \mathrm{C}$.

Immunostaining with antibodies to human lamin $\mathrm{A} / \mathrm{C}$ (Vector Laboratories, Peterborough, UK) and human spectrin (Vector Laboratories, Peterborough, UK) was performed as described previously $[5,7,9]$. For staining of sections of $m d x$ nude muscles, mouse Ig blocking reagent (Vector Laboratories, Peterborough, UK) was added in the blocking solution according to the manufacturer's instructions. Muscle sections were incubated with primary antibodies for $1 \mathrm{~h}$, followed by corresponding secondary antibodies for another hour, then were mounted with mounting medium (DAKO, Ely, UK) containing $10 \mu \mathrm{g} / \mathrm{ml}$ 4',6-diamidino-2-phenylindole (DAPI). Images were captured using Metamorph software using a Leica microscope.

For multi-channel immunostaining of human lamin A/C, human spectrin, Pax7 (1:100, DSHB, Iowa City, Iowa) and pan-laminin (1:2,000, Sigma-Aldrich, Dorset, UK), muscle sections were fixed with $4 \%$ paraformaldehyde (PFA) for $15 \mathrm{~min}$ at room temperature. The sections were then blocked as above and incubated with a combination of the primary antibodies for $1 \mathrm{~h}$ at room temperature, followed by a combination of Alexa-488 conjugated goat anti-mouse IgG1, Alexa-594 conjugated goat anti-mouse IgG2b and Alexa-647 conjugated goat anti-rabbit IgG $(\mathrm{H}+\mathrm{L})$ for $1 \mathrm{~h}(1: 500$ each, Invitrogen, Paisley, UK). Sections were then 
mounted and images were captured with a Zeiss LSM 710 confocal microscope (Carl Zeiss AG, Oberkochen, Germany).

\section{Quantification and statistical analysis}

To determine donor cell number and their contribution to regenerated muscle fibres, the number of human lamin $\mathrm{A} / \mathrm{C}+$ nuclei and the number of human spectrin + fibres which contain at least one human lamin $\mathrm{A} / \mathrm{C}+$ nucleus [36] were counted in the section that contained the most fibres of donor origin in each transplanted muscle and compared with one-way ANOVA or MannWhitney test using PRISM 5 software.

The total number of satellite cells or myoblasts, and the number of these cells that was of donor or host origin, within muscles that had been grafted with CD133+ cells were determined. The number of Pax7 + cells (total), Pax7+/human lamin A/C+ cells (donor) and Pax7+/human lamin A/C- cells (host) was counted and normalized to one hundred myofibres (delineated by laminin immunostaining) in a representative section of each muscle and compared between the two mouse strains with Mann-Whitney test, using PRISM 5 software.

To identify bona fide satellite cells (defined by their position under the basal lamina of muscle fibres) formed by transplanted CD133+ cells, the number of Pax7+/human lamin $\mathrm{A} / \mathrm{C}+$ cells which were located underneath the basal lamina (delineated by pan-laminin staining) were counted and normalized to one hundred myofibres in a representative section of each muscle and compared between the two mouse strains with Mann-Whitney test using PRISM 5 software.

\section{Results}

The number of nuclei and muscle fibres of donor origin is affected by modulation of the host muscle prior to engraftment

To investigate the effects of host muscle injury on donor cell transplantation efficiency, we injected either human pericytes or CD133+ cells into either $m d x$ nude or Rag2-/ $\gamma$ chain-/C5- host mouse muscles that had received either irradiation or cryodamage or irradiation+cryodamage, prior to donor cell transplantation.

\section{mdx nude hosts}

When human pericytes was used as donor cells, there were $51.83 \pm 20.01,84.17 \pm 13.97$ and $110.4 \pm 56.64 \mathrm{hu}$ man lamin $\mathrm{A} / \mathrm{C}+$ cells in irradiated, cryodamaged and irradiated+cryodamaged muscles, with no significant difference among the three injury groups $(P=0.465$, one-way ANOVA). However, there were significant differences in the number of human spectrin+fibres that contained at least one human lamin $\mathrm{A} / \mathrm{C}+$ nucleus $(\mathrm{S}+\mathrm{L}$ fibres), which is a stringent criterion to identify muscle fibres of donor origin, among the three injury groups $(P=$ 0.0214 , one-way ANOVA). There were significantly more donor muscle fibres in cryodamaged $(27.83 \pm 6.421, P=$ $0.0060)$ or irradiated+cryodamaged $(18.20 \pm 7.933, P=$ $0.0267)$ than irradiated $(3.00 \pm 1.506)$ muscles.

When CD133+ cells were the donor cells, there were significant differences in the number of human lamin $\mathrm{A} / \mathrm{C}+$ nuclei among irradiated $(32.50 \pm 16.66)$, cryodamaged $(248.0 \pm 35.39)$ and irradiated+cryodamaged $(195.2 \pm 48.64)$ muscles $(P=0.0012$, one-way ANOVA). There were significantly more donor cells in cryodamaged $(P=0.0050)$ or irradiated + cryodamaged $(P=0.0222)$ than irradiated muscles. Similarly, there were significant differences in the number of $\mathrm{S}+\mathrm{L}$ fibres among the three injury groups $(P=$ 0.0008 , one-way ANOVA). There were significantly more donor fibres in cryodamaged $(107.0 \pm 14.14, P=0.0050)$ or irradiated+cryodamaged $(113.8 \pm 25.39, P=0.0102)$ than irradiated $(14.50 \pm 6.980)$ muscles.

There were no significant differences in either the number of cells, or fibres, derived from either donor stem cell types between cryodamaged and irradiated+cryodamaged muscles (Table 1, Figures 1 and 2).

\section{Rag2-/ $Y$ chain-/C5- hosts}

Within muscles that had been grafted with pericytes, there were significant differences $(P=0.0424$, one-way ANOVA) in the number of human lamin $\mathrm{A} / \mathrm{C}+$ cells among the three injury groups. There were significantly more human lamin A/C+ cells in cryodamaged (270.9 \pm 76.12, $P=0.0286)$ or irradiated+cryodamaged (270.1 \pm $69.51, P=0.0416)$ than irradiated $(79.55 \pm 31.13)$ muscles. There were also significant differences $(P=0.0036$, oneway ANOVA) in the number of $\mathrm{S}+\mathrm{L}$ fibres among the three injury groups. There were significantly more donor fibres in cryodamaged $(132.6 \pm 35.37, P=0.0032)$ or irradiated+cryodamaged $(69.82 \pm 21.01, P=0.0207)$ than irradiated $(15.64 \pm 6.328)$ muscles.

Similarly, when CD133+ cells were transplanted, there were significant differences in the number of human lamin $\mathrm{A} / \mathrm{C}+$ nuclei $(P=0.0023$, one-way ANOVA $)$ and $\mathrm{S}+\mathrm{L}$ fibres $(P=0.0004)$ among the three injury groups. There were significantly more human lamin $\mathrm{A} / \mathrm{C}+$ cells in cryodamaged $(623.2 \pm 117.3, P=0.0043)$ or irradiated+cryodamaged (569.3 $\pm 104.8, P=0.0043)$ than irradiated (51.83 \pm 20.01 ) and there were also significantly more $\mathrm{S}+\mathrm{L}$ fibres in cryodamaged (191.3 $\pm 37.04, P=0.0050)$ or irradiated+cryodamaged $(146.7 \pm 18.38, P=0.0050)$ than in irradiated (18.00 \pm 6.583$)$ muscles.

There was no difference in the number of donor cells and donor muscle fibres between cryodamaged and irradiated+cryodamaged muscles, regardless of the muscle stem cell type grafted (Table 1, Figures 1 and 3). 
Table 1 The transplantation efficiency of human muscle stem cells is affected by the type of injury

\begin{tabular}{|c|c|c|c|c|c|}
\hline \multirow{3}{*}{$\begin{array}{l}\text { Donor cells } \\
\text { Host mouse }\end{array}$} & \multirow[t]{3}{*}{ Donor contribution } & \multicolumn{3}{|l|}{ Injury model } & \multirow{3}{*}{$\begin{array}{l}P \text { value } \\
\text { (one-way } \\
\text { ANOVA) }\end{array}$} \\
\hline & & \multicolumn{3}{|c|}{ Number of donor nuclei or fibres (mean \pm SEM $(n)$ ) } & \\
\hline & & Irradiation & Cryodamage & Irra+Cryo & \\
\hline \multirow[t]{2}{*}{ Pericytes $m d x$ nude } & Human lamin $A / C+$ nuclei & $51.83 \pm 20.01(6)$ & $84.17 \pm 13.97(6)$ & $110.4 \pm 56.64(5)$ & 0.465 \\
\hline & S+L fibres & $3.000 \pm 1.506(6)$ & $27.83 \pm 6.421(6)$ & $18.20 \pm 7.933(5)$ & $0.0214^{*}$ \\
\hline \multirow[t]{2}{*}{ CD133+ mdx nude } & Human lamin $A / C+$ nuclei & $32.50 \pm 16.66(6)$ & $248.0 \pm 35.39(6)$ & $195.2 \pm 48.64(5)$ & $0.0012^{* *}$ \\
\hline & S+L fibres & $14.50 \pm 6.980(6)$ & $107.0 \pm 14.14(6)$ & $113.8 \pm 25.39(5)$ & $0.0008^{* * *}$ \\
\hline \multirow[t]{2}{*}{ Pericytes Rag2-/Y chain-/C5- } & Human lamin $A / C+$ nuclei & $79.55 \pm 31.13(11)$ & $270.9 \pm 76.12(8)$ & $270.1 \pm 69.51(11)$ & $0.0424^{*}$ \\
\hline & S+L fibres & $15.64 \pm 6.33(11)$ & $132.6 \pm 35.37(8)$ & $69.82 \pm 21.01(11)$ & $0.0036^{* *}$ \\
\hline \multirow[t]{2}{*}{ CD133+ Rag2-/Y chain-/C5- } & Human lamin $A / C+$ nuclei & $98.83 \pm 44.22(6)$ & $623.2 \pm 117.3(6)$ & $569.3 \pm 104.8(6)$ & $0.0023^{* *}$ \\
\hline & S+L fibres & $18.00 \pm 6.583(6)$ & $191.3 \pm 37.04(6)$ & $146.7 \pm 18.38(6)$ & $0.0004^{* * *}$ \\
\hline
\end{tabular}

${ }^{*} P<0.05 ;{ }^{* *} P<0.01 ;{ }^{* * *} P<0.001$.

The number of nuclei and muscle fibres of donor origin is affected by the host mouse strain

To compare the transplantation efficiency in both host mouse strains, we transplanted the same CD133+ cells at the same time into Rag2-/ $\gamma$ chain-/C5- and $m d x$ nude mice (experiment 4, Additional file 1: Table S1, Table 2). Within $m d x$ nude hosts, there were similar numbers of nuclei and muscle fibres of donor origin as in the previous experiment (experiment 2, Additional file 1: Table S1; Table 1).

Within irradiated host muscles, there were no differences $(P=0.5045)$ in the number of human lamin $\mathrm{A} / \mathrm{C}+$ nuclei between Rag2-/ $\gamma$ chain-/C5- $(98.83 \pm 44.22)$ and $m d x$ nude $(57.67 \pm 39.76)$ hosts. Also, there were no differences $(P=0.9339)$ in the number of $\mathrm{S}+\mathrm{L}$ fibres be-

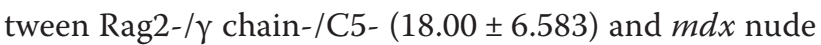
$(19.17 \pm 12.02)$ mice.

When the host muscles were cryodamaged prior to grafting, there were significantly more human lamin $\mathrm{A} / \mathrm{C}+\mathrm{nu}-$ clei $(P=0.0056)$ in Rag2-/ $\gamma$ chain-/C5- mice (623.2 \pm 117.3$)$ than in $m d x$ nude mice $(184.8 \pm 42.52)$ and significantly more $\mathrm{S}+\mathrm{L}$ fibres $(P=0.0248)$ in Rag2-/ $\gamma$ chain-/C5$(191.3 \pm 37.04)$ than in $m d x$ nude $(87.67 \pm 13.10)$ mice.

When the host muscles were irradiated+cryodamaged before cell transplantation, there were significantly more

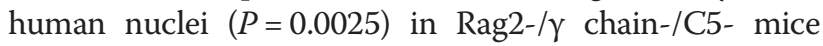
$(569.3 \pm 104.8)$ than in $m d x$ nude mice $(126.7 \pm 34.66)$ and

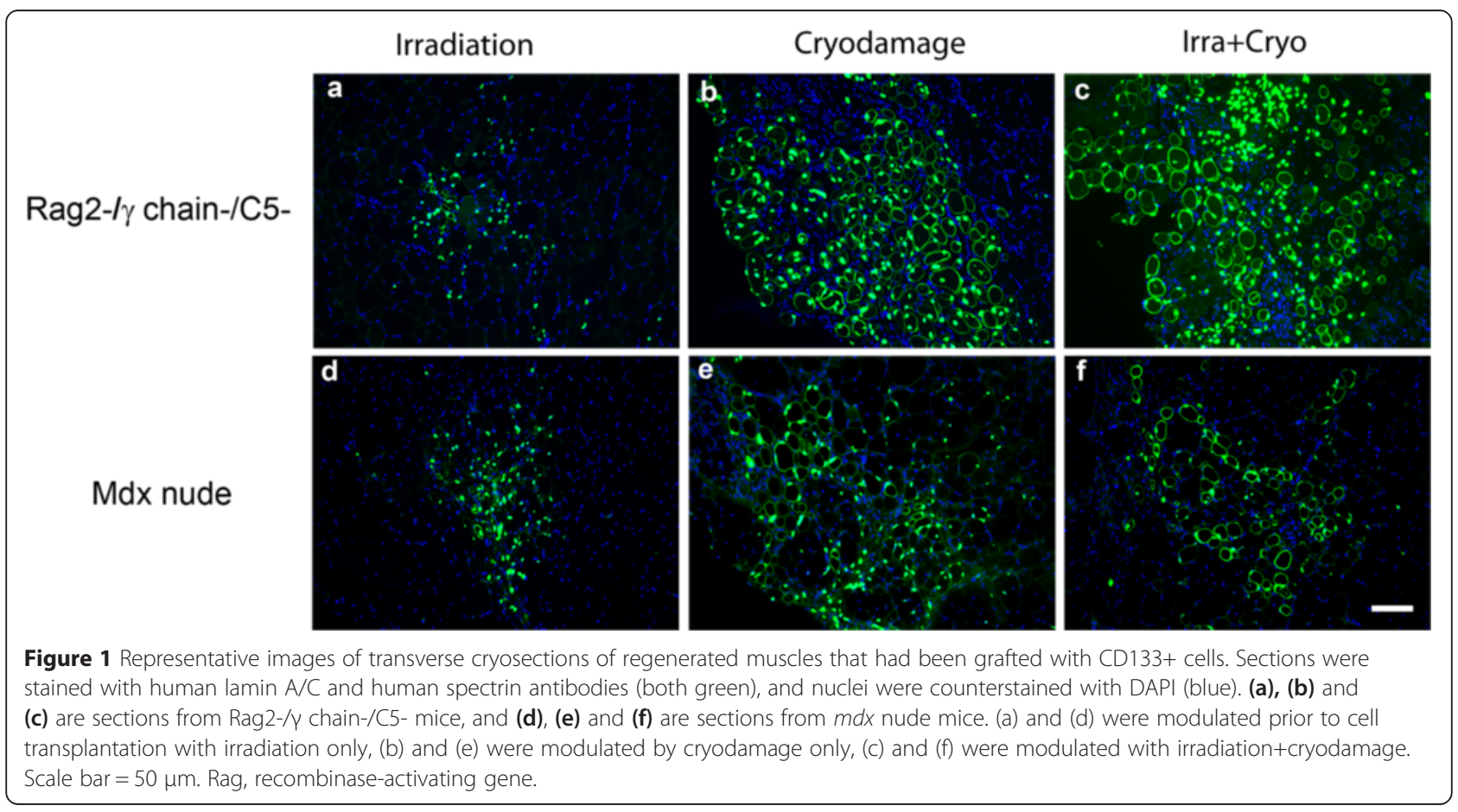




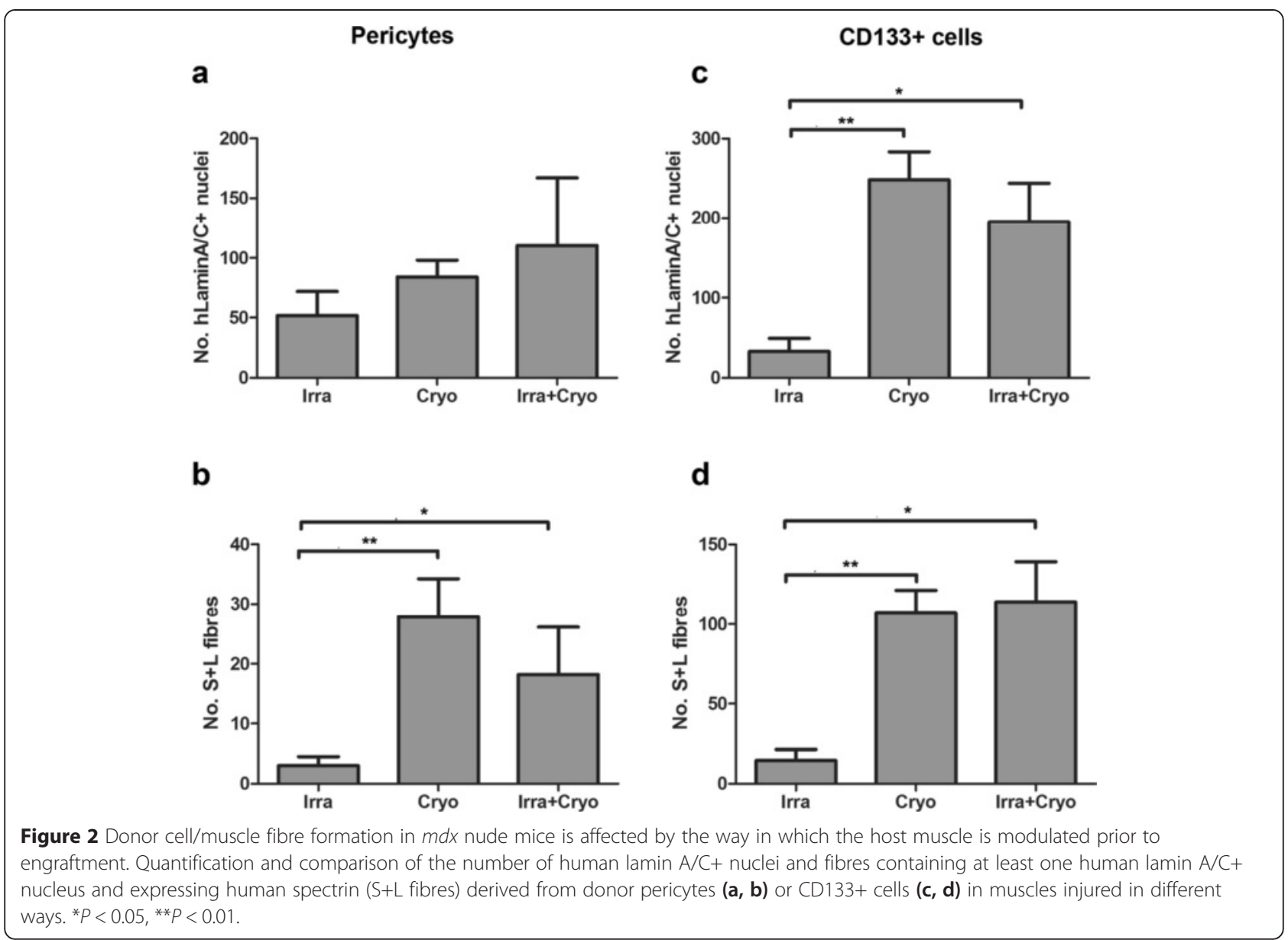

significantly more fibres of human origin $(P=0.0062)$ in Rag2- $/ \gamma$ chain-/C5- mice $(146.7 \pm 18.38)$ than in $m d x$ nude $(54.17 \pm 19.53)$ mice (Figures 1 and 4 , Table 2 ).

Donor CD133+ cells give rise to more myogenic precursor (Pax7+) cells in Rag2-/Y chain-/C5- mice than in $m d x$ nude host mice

To investigate the formation of myogenic cells (satellite cells and their progeny, myoblasts) derived from the transplanted donor cells, we compared the total number of Pax7+ myogenic cells and myogenic cells of host (Pax7+/human lamin A/C-) or donor (Pax7+/human lamin $\mathrm{A} / \mathrm{C}+$ ) origin, within grafted muscles in $\mathrm{Rag} 2-/ \gamma$ chain-/C5- and $m d x$ nude mice (Table 3 ).

Within irradiated host muscles, five out of six muscles in Rag2-/Y chain-/C5- mice contained donor-derived Pax7+ cells, and only two out of six muscles in $m d x$ nude mice contained donor-derived Pax $7+$ cells. The $n$ number in the latter group was too low for statistical analysis. Therefore, we only compared the formation of Pax7+ cells in cryodamaged or irradiated+cryodamaged muscles between the two mouse strains.
When the host muscles were cryodamaged prior to cell transplantation, there was a similar total number $(P=$ 0.5421) of myogenic cells/100 fibres in Rag2-/ $\gamma$ chain-/C5$(9.508 \pm 1.933)$ and $m d x$ nude $(8.071 \pm 1.205)$ mice. There were $7.392 \pm 1.381$ and $7.670 \pm 13.10$ myogenic cells of host origin/100 fibres in Rag2-/ $\gamma$ chain-/C5- and $m d x$ nude mice, respectively, with no difference $(P=0.9409)$ between the two mouse strains. There were $2.116 \pm 0.779$ donor-derived myogenic cells/100 fibres in Rag2- $/ \gamma$ chain-/C5- mice and $0.550 \pm 0.3$ in $m d x$ nude mice, representing $20.67 \% \pm 4.430 \%$ and $5.868 \% \pm 2.840 \%$ of the total myogenic cells in Rag2-/ $\gamma$ chain-/C5- and $m d x$ nude mice, respectively. There were no statistically significant differences in the number $(P=0.0904)$ of donor-derived myogenic cells/100 fibres between the two mouse strains; however, there was a significantly higher percentage $(P=$ 0.0184 ) of donor myogenic cells/100 fibres in Rag2- $/ \gamma$ chain-/C5- than $m d x$ nude mice (Figure 5).

When the host muscles were irradiated+cryodamaged prior to cell transplantation, there was a similar total number $(P=0.9372)$ of myogenic cells $/ 100$ fibres in Rag2- $/ \gamma$ chain-/C5- (3.320 \pm 0.7494$)$ and $m d x$ nude (3.464 \pm 0.7909$)$ 

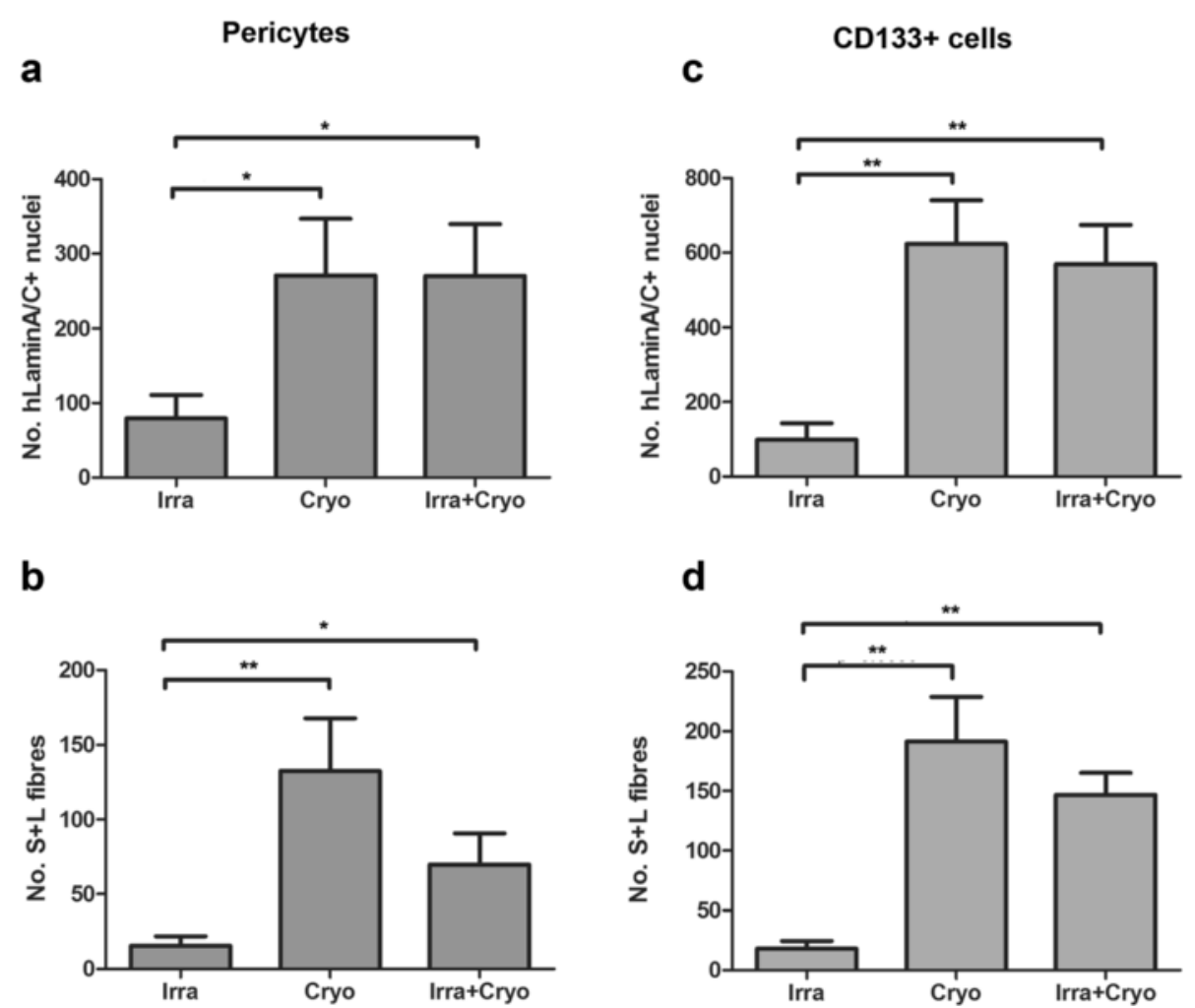

Figure 3 Donor cell/muscle fibre formation in Rag2-/Y chain-/C5- mice is affected by the way in which the host muscle is modulated prior to engraftment. Quantification and comparison of the number of human lamin $A / C+$ nuclei and $S+L$ fibres derived from donor pericytes $(\mathbf{a}$, $\mathbf{b})$ or CD133+ cells $(\mathbf{c}, \mathbf{d})$ in muscles injured in different ways. ${ }^{*} P<0.05,{ }^{* *} P<0.01$. Rag, recombinase-activating gene.

mice. There were significantly fewer $(P=0.0144)$ myogenic cells of host origin/100 fibres in Rag2- $/ \gamma$ chain-/C5$(0.7452 \pm 0.217)$ than $m d x$ nude $(3.019 \pm 0.7382)$ mice, whereas there were significantly more $(P=0.0346)$ donorderived myogenic cells/100 fibres in Rag2-/ $\gamma$ chain-/C5$(2.574 \pm 0.8427)$ than $m d x$ nude $(0.4451 \pm 0.2199)$ mice, representing $67.98 \% \pm 10.45 \%$ and $11.46 \% \pm 5.248 \%$, respectively, of the total myogenic cells in Rag2-/Y chain- $/$ C5- and $m d x$ nude mice. There was a significantly higher percentage $(P=0.0007)$ of donor myoblasts in Rag2- $/ \gamma$ chain-/C5- than $m d x$ nude mice (Figure 5).
Donor CD133+ cells make a greater contribution to the stem cell pool in Rag2-/ $Y$ chain-/C5- than $m d x$ nude host muscles

The above data compared the number of Pax7+ cells, which includes activated myogenic precursor cells and quiescent satellite cells. To evaluate the potential of donor cells to reconstitute the muscle stem cell pool within the different host muscle environments, we further quantified the percentage of grafted cells that are satellite cells. As pericytes do not give rise to Pax7+ cells within grafted muscles (Additional file 2: Figure S1),

Table 2 CD133+ donor cells have a higher transplantation efficiency in Rag2-/ $\gamma$ chain-/C5- than in mdx nude mice

\begin{tabular}{|c|c|c|c|c|}
\hline \multirow[t]{3}{*}{ Donor contribution } & \multirow{3}{*}{$\begin{array}{l}\text { Injury } \\
\text { model }\end{array}$} & \multicolumn{2}{|l|}{ Host mouse } & \multirow{3}{*}{$\begin{array}{l}P \text { value } \\
\text { (Mann-Whitney test) }\end{array}$} \\
\hline & & \multicolumn{2}{|c|}{ Number of donor fibres (mean \pm SEM $(n)$ ) } & \\
\hline & & Rag2-// chain-/C5- & $m d x$ nude & \\
\hline \multirow[t]{3}{*}{ Human lamin $\mathrm{A} / \mathrm{C}+$ nuclei } & Irradiation & $98.83 \pm 44.22(6)$ & $57.67 \pm 39.76(6)$ & 0.3281 \\
\hline & Cryodamage & $623.2 \pm 117.3(6)$ & $184.8 \pm 42.52(6)$ & $0.0087^{* *}$ \\
\hline & Irra+Cryo & $569.3 \pm 104.8(6)$ & $126.7 \pm 34.66(6)$ & $0.0087^{* *}$ \\
\hline \multirow[t]{3}{*}{$S+L$ fibres } & Irradiation & $18.00 \pm 6.583(6)$ & $19.17 \pm 12.02(6)$ & 0.7440 \\
\hline & Cryodamage & $191.3 \pm 37.04(6)$ & $87.67 \pm 13.10(6)$ & $0.0152^{*}$ \\
\hline & Irra+Cryo & $146.7 \pm 18.38(6)$ & $54.17 \pm 19.53(6)$ & $0.0087^{* *}$ \\
\hline
\end{tabular}

${ }^{*} P<0.05 ; * * P<0.01$. 


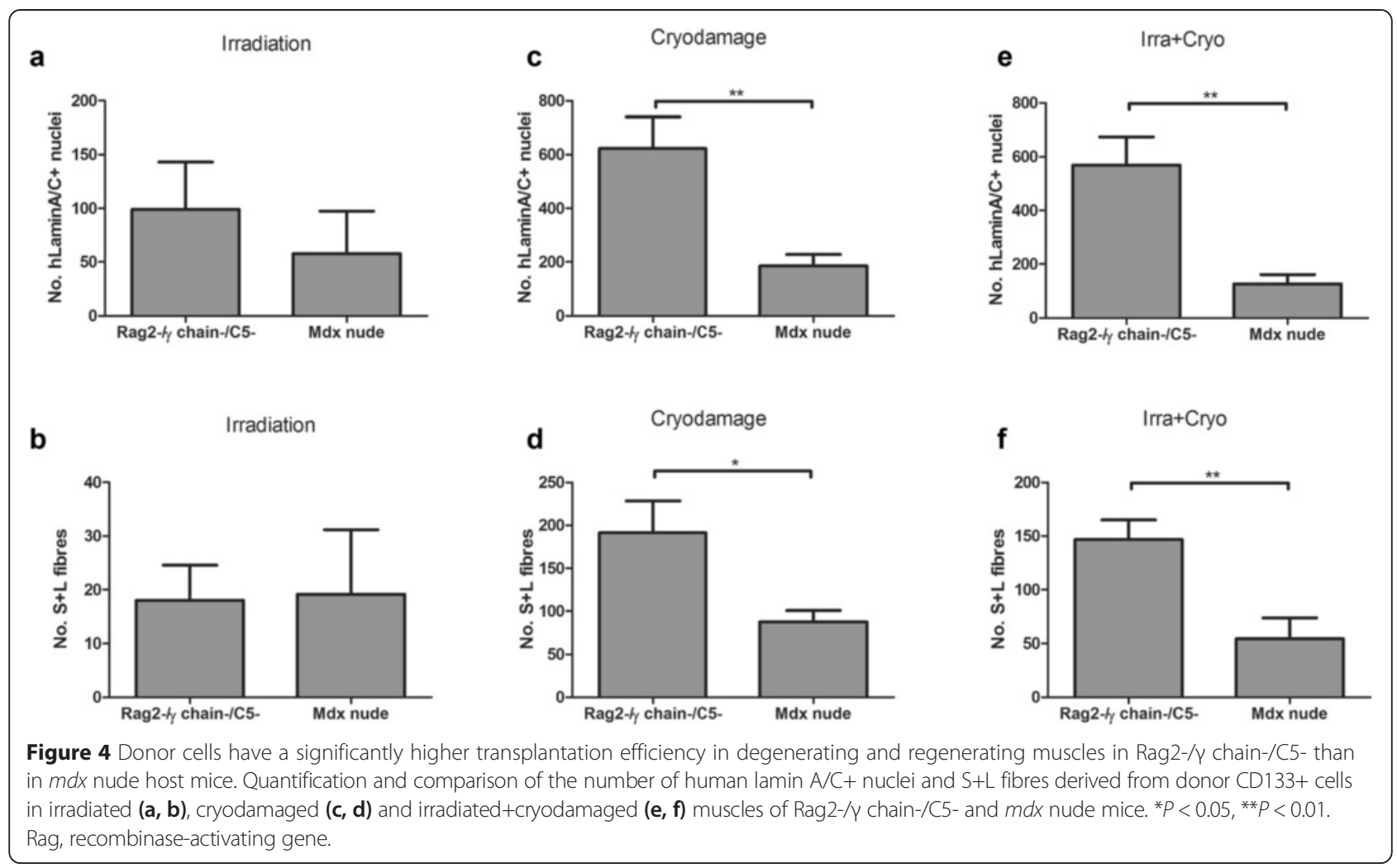

satellite cells of donor origin (Pax7+/human lamin A/C+ cells located underneath the basal lamina) in muscles that were transplanted with CD133+ cells were quantified and compared between Rag2-/ $/$ chain-/C5- and $m d x$ nude hosts. Again, we only compared the number of donor derived satellite cells in cryodamaged or irradiated+cryodamaged muscles (Figure 6).
In cryodamaged muscles, there were $1.400 \pm 0.6211$ donor-derived satellite cells/100 muscle fibres in Rag2-/ $\gamma$ chain-/C5- hosts, whereas in the $m d x$ nude, there were only $0.2220 \pm 0.1234$ donor-derived satellite cells $/ 100$ fibres. There were significant differences $(P=0.0303)$ in the number of donor-derived satellite cells between the two mouse strains.

Table 3 Pax7+ myogenic cells in muscles of Rag2-/ $/$ chain-/C5- and $m d x$ nude mice that had been grafted with CD133+ cells

\begin{tabular}{|c|c|c|c|c|}
\hline & \multirow{2}{*}{$\begin{array}{l}\text { Injury } \\
\text { models }\end{array}$} & \multicolumn{2}{|c|}{ Host mouse (mean \pm SEM $(n))$} & \multirow{2}{*}{$\begin{array}{l}P \text { value } \\
\text { (Mann-Whitney test) }\end{array}$} \\
\hline & & Rag2-/g chain-/C5- & mdx nude & \\
\hline \multirow[t]{2}{*}{ Total Pax7+ cells } & Cryodamage & $9.508 \pm 1.933(6)$ & $8.071 \pm 1.205(6)$ & 0.3095 \\
\hline & Irra+Cryo & $3.320 \pm 0.7494(6)$ & $3.464 \pm 0.7909(6)$ & 0.9372 \\
\hline \multirow[t]{2}{*}{ Host Pax7+ cells } & Cryodamage & $7.392 \pm 1.381(6)$ & $87.67 \pm 13.10(6)$ & 0.9372 \\
\hline & Irra+Cryo & $0.7452 \pm 0.217(6)$ & $3.019 \pm 0.738(6)$ & $0.0411^{*}$ \\
\hline \multirow[t]{2}{*}{ Donor Pax7+ cells } & Cryodamage & $2.116 \pm 0.7793(6)$ & $0.5501 \pm 0.3004(6)$ & 0.0931 \\
\hline & Irra+Cryo & $2.574 \pm 0.8427(6)$ & $0.4451 \pm 0.2199(6)$ & $0.0152^{*}$ \\
\hline \multirow[t]{2}{*}{ Percentage of donor Pax7+ cells } & Cryodamage & $20.67 \pm 4.430(6)$ & $5.868 \pm 2.840(6)$ & $0.026^{*}$ \\
\hline & Irra+Cryo & $67.98 \pm 10.45(6)$ & $11.46 \pm 5.248(6)$ & $0.0064^{* *}$ \\
\hline \multirow[t]{2}{*}{ Donor-derived satellite cells } & Cryodamage & $1.400 \pm 0.6211(6)$ & $0.2220 \pm 0.1234(6)$ & $0.0303^{*}$ \\
\hline & Irra+Cryo & $0.7798 \pm 0.2294(6)$ & $0.1331 \pm 0.0474(6)$ & $0.0173^{*}$ \\
\hline
\end{tabular}

${ }^{*} P<0.05 ;{ }^{*} P<0.01$. 




d

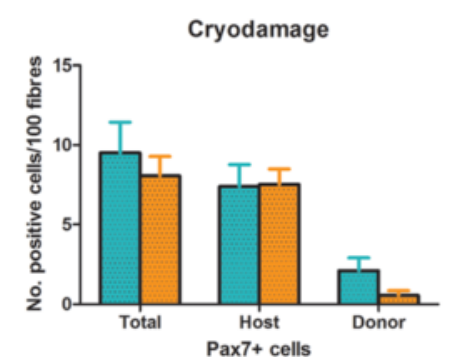

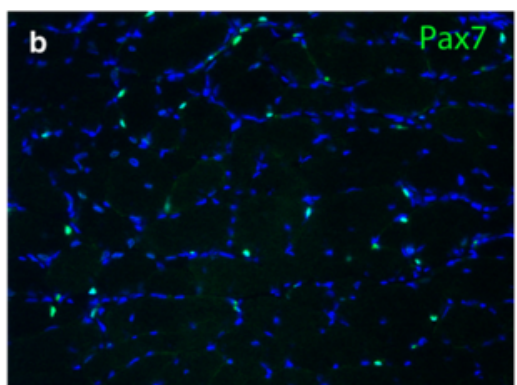

e

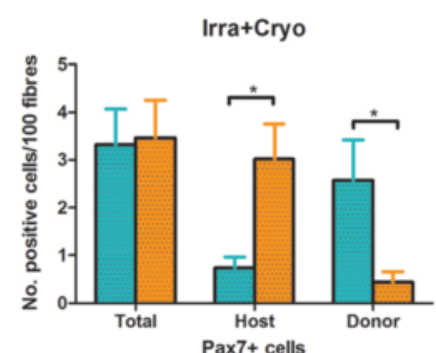



$\mathbf{f}$

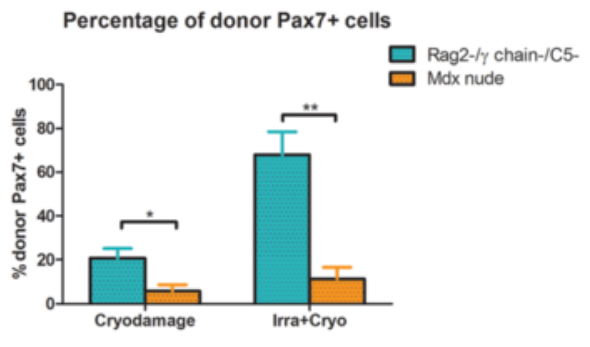

Figure 5 Myogenic cells of donor origin within regenerated host muscles. (a-c) Representative images of transverse cryosections of Rag2-/ $Y$ chain-/C5- host muscles that had been cryodamaged and transplanted with human CD133+ cells, stained with antibodies to human lamin A/C ((a), red) and Pax7 ((b), green). Nuclei were counterstained with DAPI (blue). (c) Merged image of human lamin A/C (red), Pax7 (green) and DAPI (blue). Scale bar $=25 \mu \mathrm{m}$. (d) The number of Pax7+ cells, Pax7+/human lamin A/C+ and Pax7+/human lamin A/C- cells per 100 muscle fibres in cryodamaged muscles of Rag2-// chain-/C5- and mdx nude mice. (e) the number of Pax7+ cells, Pax7+/human lamin A/C+ and Pax7+/human lamin A/C- cells per 100 muscle fibres in irradiated+cryodamaged muscles of Rag2-/ $/ y$ chain-/C5- and mdx nude mice. (f) Percentage of donor-derived myogenic cells in each injury model. ${ }^{*} P<0.05,{ }^{* *} P<0.01$. Rag, recombinase-activating gene.
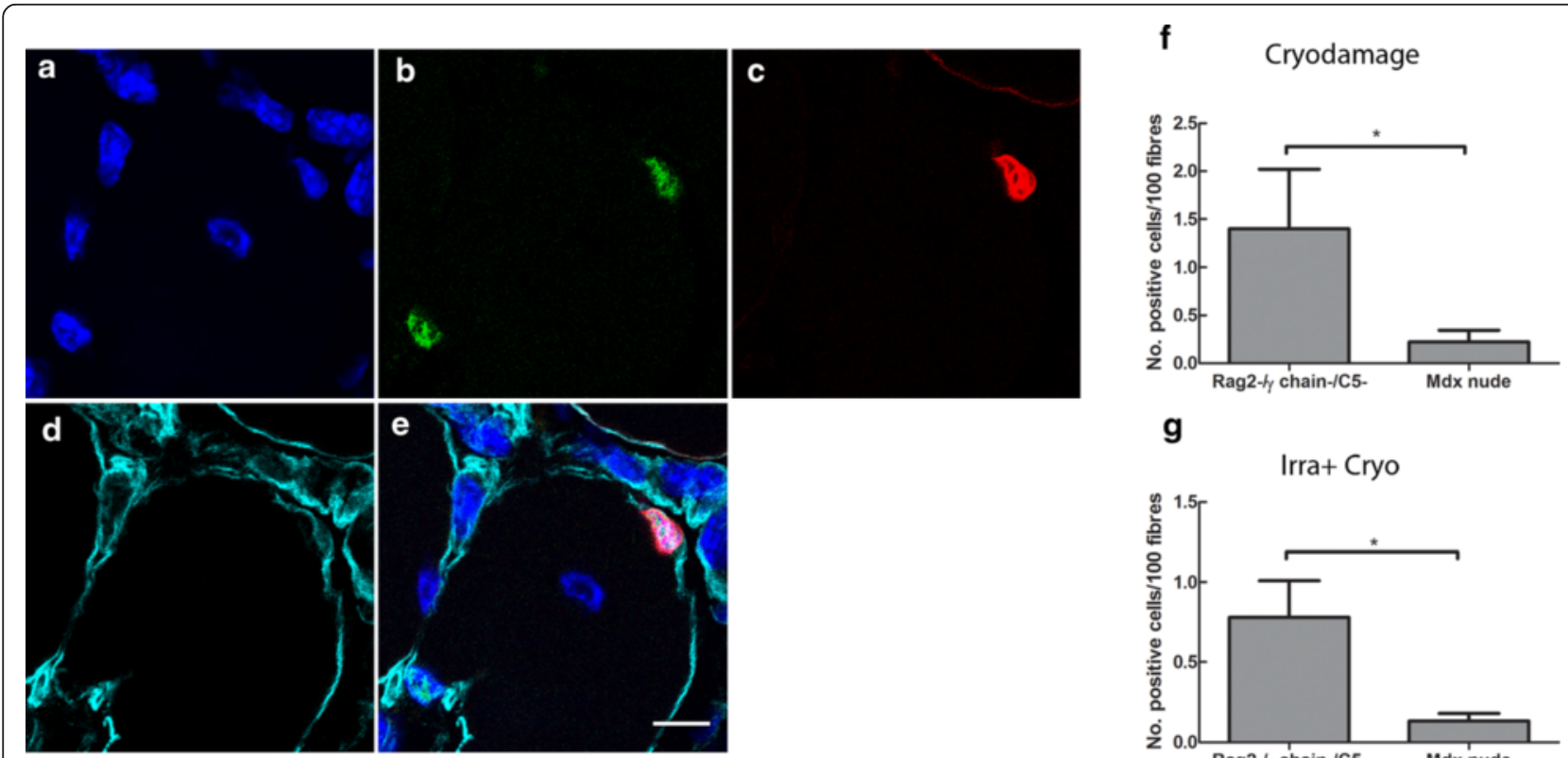

g

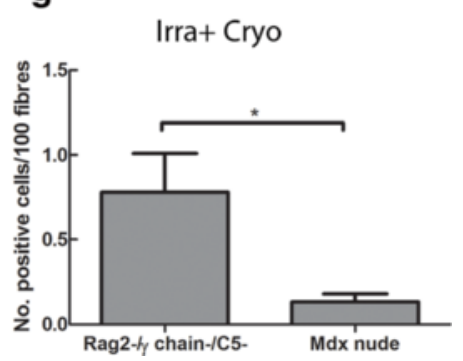

Figure 6 CD133+ cells contribute to more satellite cells in cryodamaged Rag2-/Y chain-/C5- than in mdx nude muscle. (a-e) Representative images showing donor-derived satellite cells that express Pax7 (green, (b)) and human lamin A/C (red, (c)), located underneath the basal lamina (cyan,

(d)) of the muscle fibres. Nuclei were counterstained with DAPI (blue, (a)). (e) The merged image of (a-d). Scale bar $=10 \mu$ m. (f) and (g): quantification of the percentage of donor derived satellite cells in cryodamaged (f) or irradiated+cryodamaged (Irra+Cryo, (g)) muscles of Rag2-/Y chain-/C5- and mdx nude mice. ${ }^{*} P<0.05$. Rag, recombinase-activating gene. 
When muscles had been pre-injured by irradiation+cryodamage, the number of donor-derived satellite cells/100 fibres in Rag2-/ $\gamma$ chain-/C5- and $m d x$ nude mice was $0.7798 \pm 0.2294$ and $0.1331 \pm 0.0474$, respectively, a significant difference between the two mouse strains $(P=0.0173)$.

\section{Discussion}

Although different immunodeficient host mouse strains and different host muscle pre-injury regimes have been used by for human muscle stem cell transplantation (Rag2-/ $\gamma$ chain-/C5- hosts: irradiation or cryodamage; Rag1- and SCID hosts: irradiation followed by either $\mathrm{BaCl}_{2}$, or $\mathrm{NaH}_{2} \mathrm{PO}_{4}$, or cryodamage/crush, or cryodamage alone) and some appear to permit more efficient donor muscle formation than others $[7,20]$, no comparison regarding the capability of donor stem cells to replenish the satellite cell pool in different animal models has been made. Here, we used two different types of human skeletal muscle stem cells - pericytes and CD133+ cells - as donor cells. We grafted these into two commonly used immunodeficient host mouse strains: $m d x$ nude [31], whose muscles lack dystrophin and consequently undergo rounds of muscle degeneration and regeneration, and Rag2-/Y chain-/C5- mice [16], whose muscles have no pathology. In regenerated grafted muscles, we compared the number of nuclei, muscle fibres and satellite cells of donor origin.

\section{Effects of the injury models}

How the host muscle is best modulated to promote efficient donor cell engraftment is not clear. This may depend on the pathological status of the host muscle or the type or species of origin of the donor cells. Irradiation kills most of the host satellite cells but spares the muscle fibres and preserves the satellite cell niche [14]. Cryodamage kills muscle fibres and most satellite cells but would also activate surviving host satellite cells. The combination of 18-Gy irradiation and cryodamage would destroy muscle fibres and kill most of the host satellite cells, thus ablating the satellite cell niche. But in irradiated muscles, radiation-resistant stem cells contribute to muscle regeneration following injury [14,37]. Each model therefore provides different environmental cues to donor cells.

We found that there were significantly more nuclei and muscle fibres of donor origin in host muscles that had been modulated by cryoinjury, or cryoinjury+irradiation, than by irradiation alone. This is host mouse strain independent, suggesting that in cryodamaged and irradiated+cryodamaged muscles, environmental changes are more permissive for human muscle stem cells than in irradiated muscles. In addition to degeneration and regeneration, massive infiltration of myeloid cells elicited by muscle injury is a factor known to control the fate of donor human myoblasts [18,38] and mouse mesoangioblasts $[39,40]$. Interaction between human pericytes or CD133+ cells and myeloid populations in a muscle environment are largely unknown, but our data suggest these muscle stem cells, as do myoblasts, respond to inflammatory stimuli.

Irradiation is known to promote the proliferation of donor mouse myoblasts [41], and this may be mediated by an alteration in the composition of the extracellular matrix [13]. However, in comparison with cryoinjury, irradiation of the host muscle 3 days before donor human stem cell transplantation does little or nothing to augment donor contribution to regenerated host muscle (Figures 1 and 2 and Tables 1 and 2). This is in contrast to our previous findings on mouse satellite cell transplantation into $m d x$ nude hosts [14]. Also in contrast to donor mouse satellite cells [14], donor human skeletal muscle-derived stem cells function well within a cryoinjured host muscle environment. One possible reason for this is that donor cells from different species react differently to pro-inflammatory factors within the injured host muscle environment [42].

Our data clearly show that cryodamage prior to cell transplantation effectively elicits robust donor cell engraftment and that combining irradiation with cryodamage has no additive effect on the contribution of transplanted cells to muscle regeneration. However, the percentage of Pax7+ cells of donor origin was significantly higher in irradiated+cryodamaged than in cryodamaged Rag2-/ $\gamma$ chain-/C5- host mouse muscles (Figure 5f).

\section{Effects of the mouse strain}

Different mouse strains present different environments for donor human muscle stem cells. Rag2-/Y chain-/C5mice have a more profound immunodeficiency than the $m d x$ nude mouse, while the latter is dystrophin deficient and its muscles exhibit pathological features, such as muscle degeneration and regeneration, accompanied by the infiltration of inflammatory cells.

The influence of the host mouse strain on transplantation efficiency was most clearly shown when the host muscle was challenged with profound damage, that is, cryodamage or irradiation+cryodamage. Under such conditions, there were significantly more nuclei, muscle fibres and satellite cells of donor origin in Rag2- $/ \gamma$ chain-/C5- than $m d x$ nude mouse.

An interesting finding was that the ratio of the donor and host-derived Pax7+ cells within the grafted muscles was also different. Within transplanted cryoinjured muscles in both host stains, the majority of the muscle stem/ precursor cell pool was host derived (Figure 5d). However, in irradiated+cryodamaged muscles, the Pax7+ cells were mainly of donor origin in Rag2-/ $\gamma$ chain-/C5- mice 
but were mainly of host origin in $m d x$ nude mice (Figure 5e).

These differences in transplantation efficiency between the two strains may be due either to differences in their genetic background (both host mouse strains are on mixed, and different, genetic backgrounds), their immunological status or the pathological state of the host muscle. Further studies focusing on identifying the main factors responsible for augmenting donor muscle and satellite cell formation within dystrophic muscle are required to enable a long-term and effective stem cell therapy to DMD.

Although we and others [11] have shown that donor CD133+ cells derived from non-dystrophic donor muscle gave rise to Pax7+ cells following their engraftment, pericytes derived from DMD skeletal muscle did not. It remains to be seen whether CD133+ cells derived from DMD muscle can give rise to satellite cells. But satellite cells from $m d x$ muscles give rise to functional satellite cells when transplanted into a permissive environment [43] - evidence that stem cells derived from a dystrophic muscle environment can be perfectly functional.

\section{Conclusions}

The transplantation efficiency of human muscle stem cells is affected by both the local host mouse muscle environment and the host mouse strain. Cryoinjured muscles of Rag2-/ $\gamma$ chain-/C5- mice provide the most permissive environment for testing the contribution of intra-muscularly transplanted human skeletal musclederived stem cells to muscle regeneration. Although $m d x$ nude host mouse muscles provide an environment in which there is significantly less donor human stem cell engraftment than do Rag2-/ $\gamma$ chain-/C5- mice, they nevertheless still permit donor-derived muscle regeneration. The advantage of such a dystrophin-deficient model is that the functionality of dystrophin restored by normal donor stem cells can be investigated.

\section{Additional files}

Additional file 1: Table S1. Details of transplantation experiments. Details of the donor cells, host mice, muscle injury models and numbers of transplanted muscles in each experiment.

Additional file 2: Figure S1. Human pericytes do not give rise to Pax7 + myogenic cells following their transplantation in vivo. Representative images showing the co-immunostaining of human lamin $A / C$, human spectrin (a, both red) and Pax7 (b, green) on transverse cryosections of Rag2-/Y chain-/C5- host muscles that had been cryodamaged and transplanted with human pericytes. There were no human lamin $\mathrm{A} / \mathrm{C}+/ \mathrm{Pax} 7+$ nuclei present within the muscle. Nuclei were counterstained with DAPI (c, blue). Scale bar $=50 \mu \mathrm{m}$.

\section{Abbreviations}

DAPI: 4',6-diamidino-2-phenylindole; DMD: Duchenne muscular dystrophy; PFA: paraformaldehyde; Rag: recombinase-activating gene; $S+L$ fibres: Human spectrin and human lamin A/C positive fibres; SCID: severe combined immune deficient; TA: tibialis anterior.
Competing interests

The authors declare that they have no competing interests.

\section{Authors' contributions}

JM, MB, RA, FM and JEM have made substantial contributions to the conception and design, acquisition of data, or analysis and interpretation of data and have been involved in drafting the manuscript or revising it critically for intellectual content. All authors have given final approval of the final manuscript and agreed to be accountable for all aspects of the work in ensuring that questions related to the accuracy or integrity of any part of the work are appropriately investigated and resolved.

\section{Acknowledgements}

The support of the MRC Centre for Neuromuscular Diseases Biobank and Diana Johnson are gratefully acknowledged. The Pax7 antibody developed by A. Kawakami was obtained from the Developmental Studies Hybridoma Bank developed under the auspices of the National Institute of Child Health and Human Development and maintained by the University of lowa, Department of Biological Sciences, lowa City, IA.

\section{Funding}

This work was funded by the MRC. MB was funded by AFM. JEM was funded by a Wellcome Trust University Award and is currently funded by the Great Ormond Street Children's Charity. The support of the Great Ormond Street Hospital Biomedical Research Centre to FM is also gratefully acknowledged.

Received: 26 January 2015 Accepted: 12 March 2015

Published online: 28 April 2015

\section{References}

1. Morizumi H, Hizawa K, Nunomura S, li K. Comparative study of alterations of skeletal muscle in Duchenne muscular dystrophy and polymyositis. Acta Pathol Jpn. 1984;34:1221-42.

2. Arpke RW, Darabi R, Mader TL, Zhang Y, Toyama A, Lonetree $C L$, et al. $A$ new immuno-, dystrophin-deficient model, the NSG-mdx(4Cv) mouse, provides evidence for functional improvement following allogeneic satellite cell transplantation. Stem Cells. 2013;31:1611-20.

3. Benchaouir R, Meregalli M, Farini A, D'Antona G, Belicchi M, Goyenvalle A, et al. Restoration of human dystrophin following transplantation of exon-skipping-engineered DMD patient stem cells into dystrophic mice. Cell Stem Cell. 2007;1:646-57.

4. Dellavalle A, Sampaolesi M, Tonlorenzi R, Tagliafico E, Sacchetti B, Perani L, et al. Pericytes of human skeletal muscle are myogenic precursors distinct from satellite cells. Nat Cell Biol. 2007;9:255-67.

5. Meng J, Adkin CF, Xu SW, Muntoni F, Morgan JE. Contribution of human muscle-derived cells to skeletal muscle regeneration in dystrophic host mice. PLoS One. 2011;6, e17454.

6. Vallese D, Negroni E, Duguez S, Ferry A, Trollet C, Aamiri A, et al. The Rag2(-)\|2rb(-)Dmd(-) mouse: a novel dystrophic and immunodeficient model to assess innovating therapeutic strategies for muscular dystrophies. Mol Ther. 2013;21:1950-7.

7. Brimah K, Ehrhardt J, Mouly V, Butler-Browne GS, Partridge TA, Morgan JE. Human muscle precursor cell regeneration in the mouse host is enhanced by growth factors. Hum Gene Ther. 2004;15:1109-24.

8. Cooper RN, Irintchev A, Di Santo JP, Zweyer M, Morgan JE, Partridge TA, et al. A new immunodeficient mouse model for human myoblast transplantation. Hum Gene Ther. 2001;12:823-31.

9. Meng J, Adkin CF, Arechavala-Gomeza V, Boldrin L, Muntoni F, Morgan JE. The contribution of human synovial stem cells to skeletal muscle regeneration. Neuromuscul Disord. 2010:20:6-15.

10. Meng J, Chun S, Asfahani R, Lochmuller H, Muntoni F, Morgan J. Human skeletal muscle-derived CD133(+) cells form functional satellite cells after intramuscular transplantation in immunodeficient host mice. Mol Ther. 2014;22:1008-17.

11. Negroni E, Riederer I, Chaouch S, Belicchi M, Razini P, Di SJ, et al. In vivo myogenic potential of human CD133+ muscle-derived stem cells: a quantitative study. Mol Ther. 2009;17:1771-8.

12. Silva-Barbosa SD, Butler-Browne GS, Di Santo JP, Mouly V. Comparative analysis of genetically engineered immunodeficient mouse strains as recipients for human myoblast transplantation. Cell Transplant. 2005;14:457-67. 
13. Silva-Barbosa SD, Butler-Browne GS, de Mello W, Riederer I, Di Santo JP, Savino W, et al. Human myoblast engraftment is improved in lamininenriched microenvironment. Transplantation. 2008;85:566-75.

14. Boldrin L, Neal A, Zammit PS, Muntoni F, Morgan JE. Donor satellite cell engraftment is significantly augmented when the host niche is preserved and endogenous satellite cells are incapacitated. Stem Cells. 2012;30:1971-84.

15. Collins CA, Olsen I, Zammit PS, Heslop L, Petrie A, Partridge TA, et al. Stem cell function, self-renewal, and behavioral heterogeneity of cells from the adult muscle satellite cell niche. Cell. 2005;122:289-301.

16. Morgan JE, Gross JG, Pagel CN, Beauchamp JR, Fassati A, Thrasher AJ, et al. Myogenic cell proliferation and generation of a reversible tumorigenic phenotype are triggered by preirradiation of the recipient site. J Cell Biol. 2002;157:693-702.

17. Sacco A, Doyonnas R, Kraft P, Vitorovic S, Blau HM. Self-renewal and expansion of single transplanted muscle stem cells. Nature. 2008. doi:10.1038/ nature07384.

18. Bencze M, Negroni E, Vallese D, Yacoub-Youssef H, Chaouch S, Wolff A, et al. Proinflammatory macrophages enhance the regenerative capacity of human myoblasts by modifying their kinetics of proliferation and differentiation. Mol Ther. 2012;20:2168-79.

19. Irintchev $\mathrm{A}$, Langer $\mathrm{M}$, Zweyer $\mathrm{M}$, Theisen $\mathrm{R}$, Wernig A. Functional improvement of damaged adult mouse muscle by implantation of primary myoblasts. J Physiol. 1997:500(Pt 3):775-85.

20. Pye D, Watt DJ, Walker C, Lightowlers RN, Turnbull DM. Identification of the RAG-1 as a suitable mouse model for mitochondrial DNA disease. Neuromuscul Disord. 2004;14:329-36.

21. Zheng B, Cao B, Crisan M, Sun B, Li G, Logar A, et al. Prospective identification of myogenic endothelial cells in human skeletal muscle. Nat Biotechnol. 2007:25:1025-34.

22. Ehrhardt J, Brimah K, Adkin C, Partridge T, Morgan J. Human muscle precursor cells give rise to functional satellite cells in vivo. Neuromuscul Disord. 2007;17:631-8.

23. Guigal N, Rodriguez M, Cooper RN, Dromaint S, Di Santo JP, Mouly V, et al. Uncoupling protein-3 (UCP3) mRNA expression in reconstituted human muscle after myoblast transplantation in RAG2-/-/gamma c/C5(-) immunodeficient mice. J Biol Chem. 2002;277:47407-11.

24. Shinkai Y, Rathbun G, Lam KP, Oltz EM, Stewart V, Mendelsohn M, et al. RAG-2-deficient mice lack mature lymphocytes owing to inability to initiate V(D)J rearrangement. Cell. 1992;68:855-67.

25. DiSanto JP, Muller W, Guy-Grand D, Fischer A, Rajewsky K. Lymphoid development in mice with a targeted deletion of the interleukin 2 receptor gamma chain. Proc Natl Acad Sci U S A. 1995;92:377-81.

26. Goldman JP, Blundell MP, Lopes L, Kinnon C, Di Santo JP, Thrasher AJ. Enhanced human cell engraftment in mice deficient in RAG2 and the common cytokine receptor gamma chain. Br J Haematol. 1998;103:335-42.

27. Partridge T. Animal models of muscular dystrophy - what can they teach us? Neuropathol Appl Neurobiol. 1991;17:353-63.

28. Whitmore C, Morgan J. What do mouse models of muscular dystrophy tell us about the DAPC and its components? Int J Exp Pathol. 2014. doi:10.1111/ iep.12095.

29. Lu QL, Morris GE, Wilton SD, Ly T, Artem'yeva OV, Strong P, et al. Massive idiosyncratic exon skipping corrects the nonsense mutation in dystrophic mouse muscle and produces functional revertant fibers by clonal expansion. J Cell Biol. 2000;148:985-96.

30. Yokota T, Lu QL, Morgan JE, Davies KE, Fisher R, Takeda S, et al. Expansion of revertant fibers in dystrophic mdx muscles reflects activity of muscle precursor cells and serves as an index of muscle regeneration. J Cell Sci. 2006;119:2679-87.

31. Partridge TA, Morgan JE, Coulton GR, Hoffman EP, Kunkel LM. Conversion of mdx myofibres from dystrophin-negative to -positive by injection of normal myoblasts. Nature. 1989;337:176-9.

32. Neal A, Boldrin L, Morgan JE. The satellite cell in male and female, developing and adult mouse muscle: distinct stem cells for growth and regeneration. PLoS One. 2012;7, e37950.

33. Ross J, Benn A, Jonuschies J, Boldrin L, Muntoni F, Hewitt JE, et al. Defects in glycosylation impair satellite stem cell function and niche composition in the muscles of the dystrophic large(myd) mouse. Stem Cells. 2012;30:2330-41.

34. Kaestner KH, Knochel W, Martinez DE. Unified nomenclature for the winged helix/forkhead transcription factors. Genes Dev. 2000;14:142-6.
35. Gross JG, Bou-Gharios G, Morgan JE. Potentiation of myoblast transplantation by host muscle irradiation is dependent on the rate of radiation delivery. Cell Tissue Res. 1999;298:371-5.

36. Rozkalne A, Adkin C, Meng J, Lapan A, Morgan J, Gussoni E. Mouse regenerating myofibers detected as false-positive donor myofibers with anti-human spectrin. Hum Gene Ther. 2013. doi:10.1089/hum.2013.

37. Heslop L, Morgan JE, Partridge TA. Evidence for a myogenic stem cell that is exhausted in dystrophic muscle. J Cell Sci. 2000;113(Pt 12):2299-308.

38. Arnold L, Henry A, Poron F, Baba-Amer Y, van Rooijen N, Plonquet A, et al. Inflammatory monocytes recruited after skeletal muscle injury switch into antiinflammatory macrophages to support myogenesis. J Exp Med. 2007;204:1057-69.

39. Bosurgi L, Corna G, Vezzoli M, Touvier T, Cossu G, Manfredi AA, et al. Transplanted mesoangioblasts require macrophage $\mathrm{IL}-10$ for survival in a mouse model of muscle injury. J Immunol. 2012;188:6267-77.

40. Lolmede K, Campana L, Vezzoli M, Bosurgi L, Tonlorenzi R, Clementi E, et al. Inflammatory and alternatively activated human macrophages attract vessel-associated stem cells, relying on separate $\mathrm{H}$. J Leukoc Biol. 2009;85:779-87.

41. Beauchamp JR, Morgan JE, Pagel CN, Partridge TA. Dynamics of myoblast transplantation reveal a discrete minority of precursors with stem cell-like properties as the myogenic source. J Cell Biol. 1999;144:1113-22.

42. Lewis M, Tartaglia LA, Lee A, Bennett GL, Rice GC, Wong GH, et al. Cloning and expression of cDNAs for two distinct murine tumor necrosis factor receptors demonstrate one receptor is species specific. Proc Natl Acad Sci U S A. 1991:88:2830-4.

43. Boldrin L, Zammit PS, Morgan JE. Satellite cells from dystrophic muscle retain regenerative capacity. Stem Cell Res. 2014;14:20-9.

\section{Submit your next manuscript to BioMed Central and take full advantage of:}

- Convenient online submission

- Thorough peer review

- No space constraints or color figure charges

- Immediate publication on acceptance

- Inclusion in PubMed, CAS, Scopus and Google Scholar

- Research which is freely available for redistribution 